\title{
Pt-Pd system: Investigation of mechanical properties
}

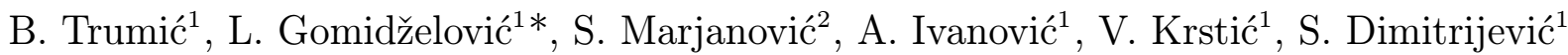 \\ ${ }^{1}$ Mining and Metallurgy Institute Bor, Zeleni bulevar 35, 19210 Bor, Serbia \\ ${ }^{2}$ University of Belgrade, Technical Faculty in Bor, VJ 12, 19210 Bor, Serbia
}

Received 11 November 2013, received in revised form 16 April 2015, accepted 11 June 2015

\begin{abstract}
To extend the future application of products based on platinum and palladium, investigation of mechanical properties of Pt-Pd alloys was conducted. Binary Pt-Pd alloys are widely used in chemical industry, electronics, and in particular for the development of laboratory instruments. Following mechanical properties were examined: hardness, microhardness, tensile strength, elongation, specific electrical resistance and relative thermal expansion, rupture time and creep rate of selected alloys. Based on the obtained results it can be concluded that alloying of platinum with palladium does not lead to a significant improvement in mechanical properties, both at room and elevated temperatures.
\end{abstract}

K e y w ords: Pt-Pd alloys, mechanical properties, high temperature

\section{Introduction}

The interest in platinum and platinum alloys constantly increases, because new areas of application are continuously discovered [1]. Today, platinum alloys, due to their characteristics such as high strength, good workability and mostly corrosion resistance at high temperatures, are present in different areas such as production of glass $[2,3]$ and nitrogen fertilizers [4-6], production of thermocouples [7], production of automotive catalysts $[8]$, jewelry $[9,10]$, etc. Recently, glucose sensors based on nanoparticles of platinum alloys with $\mathrm{Ru}, \mathrm{Pd}$, and $\mathrm{Au}$, on the carrier of carbon, have been developed [11].

The addition of palladium to platinum, as alloying element, to change the color of highly noble dental alloys has been the subject of research $[12,13]$. Thermal stability, mechanical properties and influence of palladium in thin films based on noble metals have been investigated [14-16]. Monte Carlo simulation of surface segregation of Pt-Pd and Pt-Ir alloys with an analytic embedded-atom method was done by Deng et al. [17].

Pt-Rh, Pt-Pd, Pd-Rh and Pt-Pd-Rh phase diagrams were investigated using Monte Carlo simulation method in combination with MEAM method and optimized parameters [18]. Zhang et al. [19] de- veloped carbon-supported Pd-Pt nanoalloy with low $\mathrm{Pt}$ content for formic acid electro-oxidation. Edler and Lehmann [20] studied the mechanical stability of $\mathrm{Pt} / \mathrm{Pd}$ thermocouples while Ongrai et al. [21] conducted comparative study of $\mathrm{Pt} / \mathrm{Pd}$ and $\mathrm{Pt}-\mathrm{Rh} / \mathrm{Pt}$ thermocouples stability and homogeneity. Ramirez Caballero and Balbuena [22] investigated surface segregation phenomena in $\mathrm{Pt}-\mathrm{Pd}$ nanoparticles and Hansen et al. [23] examined alloy formation and surface segregation in zeolite-supported Pt-Pd bimetallic catalysts. In a comparative analysis of the high-temperature strength of platinum and its binary alloys with a low content of alloying element, Trumić et al. [24] studied PtPd4 and PtPd10 alloys. Oxidation of ammonia on PtMe (Me = Ir, Rh, Pd, Ru) [25] was investigated to develop fuel cell based on ammonia. The influence of palladium on the reduction of platinum losses from Pt-Pd and Pt-Pd-Rh alloys and gasses produced during the oxidation of ammonia was also examined $[4,5]$. The aim of this paper is to investigate the mechanical properties of $\mathrm{Pt}-\mathrm{Pd}$ system alloys at high temperatures.

\section{Materials and investigation technique}

All experimental examinations which results are

*Corresponding author: e-mail address: lgomidzelovic@yahoo.com 
presented in this paper were carried out on platinum samples of $99.95 \%$ purity and palladium $99.5 \%$.

Platinum and rhodium for alloys production have been obtained as a side product in the production of electrolytic copper in company RTB, Serbia, technical grade. By additional refinement at Institute of Mining and Metallurgy Bor, necessary purity for samples production has been achieved. Impurities in investigated samples are characteristic for the raw material from deposits of Bor - Pd, Ag, Au, Bi, Sb, As, Cu.

Melting of samples was performed in medium frequency induction furnace. Annealing of samples was carried out in a resistance furnace, type LP08.

To determine microhardness at room temperature and tensile high-temperature strength of platinum and platinum alloys with 10 and $15 \% \mathrm{Pd}$, in the temperature range of $1100-1400{ }^{\circ} \mathrm{C}$, samples with diameter $1.3 \mathrm{~mm}$ and length of $50 \mathrm{~mm}$ were used. Before testing, samples were annealed at $1300^{\circ} \mathrm{C}$ for $3 \mathrm{~h}$. Deformation rate in tests was $6 \mathrm{~mm} \mathrm{~min}^{-1}$.

The high-temperature strength of alloys with 15, $25,50,75$ and $90 \% \mathrm{Pd}$ was also examined. After casting samples were rolled and then drawn into a wire with a diameter of $0.8 \mathrm{~mm}$, from which the $50 \mathrm{~mm}$ length samples were cut off. On those samples tests were conducted at a strain of 5 and $10 \mathrm{MPa}$ until a complete breakdown.

For testing mechanical properties of samples at high temperatures, a universal device for tensile testing of materials, maximal working temperature up to $1500^{\circ} \mathrm{C}$, by the manufacturer Karl Frank, type 81221 , was used. For testing time strength and elongation, at high temperatures, the device Mayes MK2 TC/10 (by English manufacturer) was used, with samples of standard size and shape for this type of testing. Chemical analysis of material for samples was performed by an atomic absorption spectrophotometer. The microstructure of investigated samples was monitored using an optical microscope.

\section{Results and discussion}

In this paper, characteristics of Pt-Pd system alloys were studied and tested in detail, at both room temperature and elevated temperatures at various loads. Alloys of this binary system are of great interest because of their wide application in the chemical industry, radio electronics, for making laboratory dishes, etc.

For testing the hardness, tensile strength, and elongation at room temperature, specific electrical resistivity and relative thermal expansion of samples in the temperature range $25-100^{\circ} \mathrm{C}$, for selected $\mathrm{Pt}-\mathrm{Pd}$ alloys, samples of standard sizes and shapes for this type of testing were used.

The results of the dependence of hardness, tensile

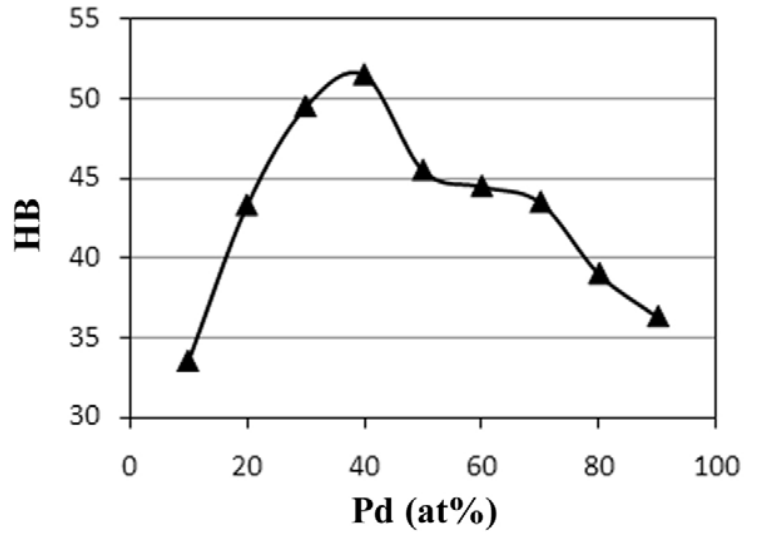

Fig. 1. Dependence of Pt-Pd alloys hardness, HB, on palladium content.

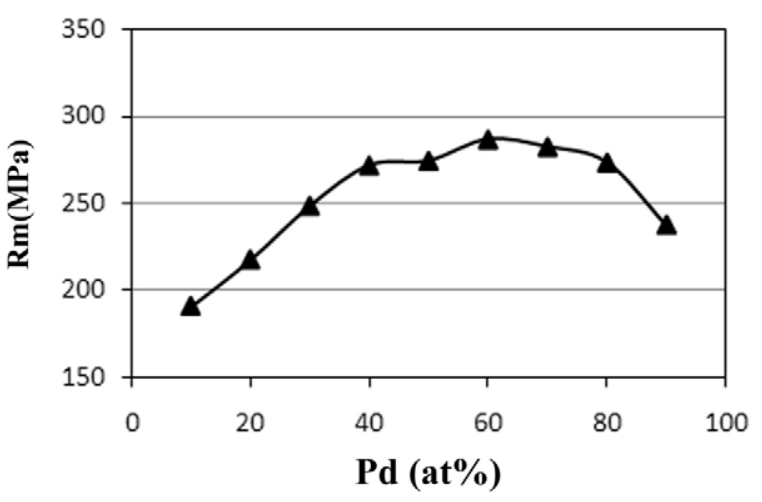

Fig. 2. Dependence of Pt-Pd alloys tensile strength, $R_{\mathrm{m}}$, on palladium content.

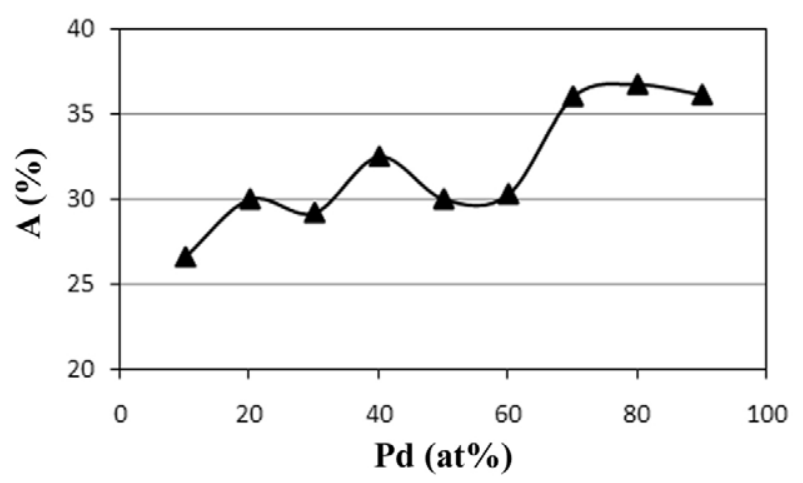

Fig. 3. Dependence of Pt-Pd alloys elongation, $A$, on palladium content.

strength and elongation of cold deformed samples on palladium content, at room temperature are shown in Figs. 1-3.

Based on the presented results, it can be concluded that hardness rises sharply to $40 \% \mathrm{Pd}$, and then slowly decreases with increasing palladium content. 


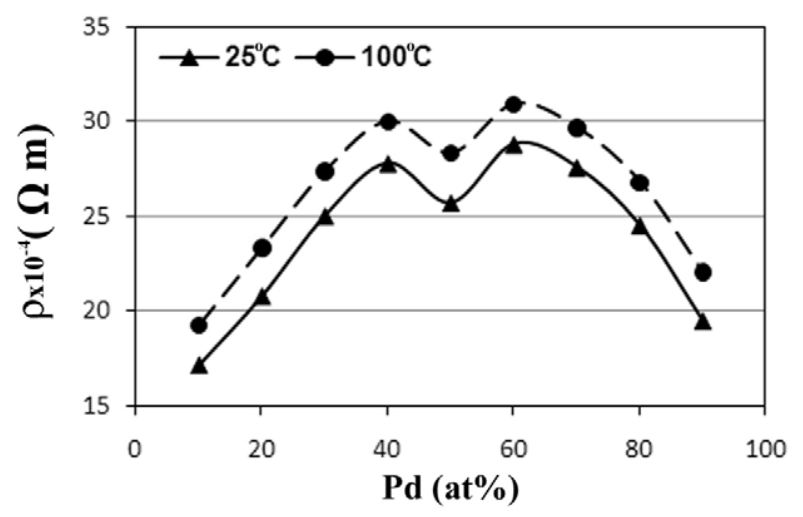

Figure 4. Dependence of Pt-Pd alloys specific electrical resistivity, $\rho$, on palladium content.

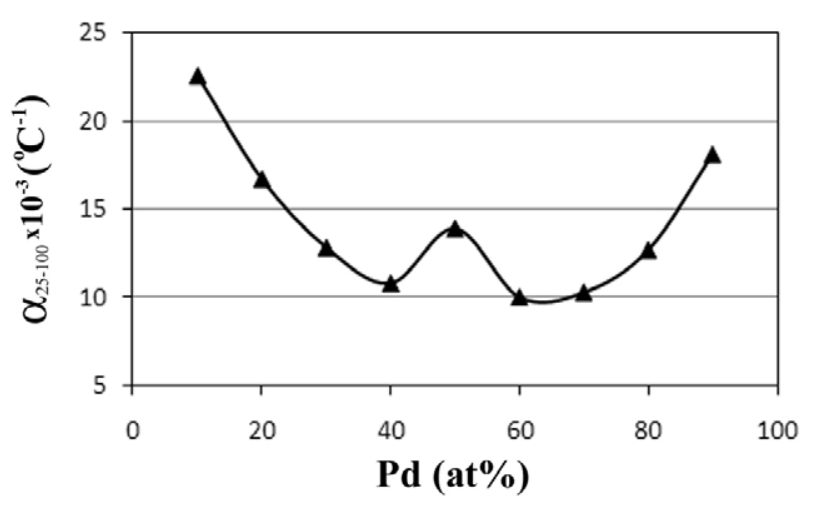

Fig. 5. Dependence of Pt-Pd alloys relative thermal expansion, $\left(\alpha_{25}-100\right)$, on palladium content.

Alloys containing 40-70\% Pd have maximum tensile strength while relative elongation increases slightly with increasing palladium content.

The results of the dependence of specific electrical resistivity and relative thermal expansion on palladium content, in the temperature range of $25-100^{\circ} \mathrm{C}$, are shown in Figs. 4, 5.

The specific electrical resistance increases with increasing palladium content up to $40 \%$, then decreases to $50 \% \mathrm{Pd}$, increases to $60 \% \mathrm{Pd}$ and with further increasing of palladium content in the alloy drops significantly. Relative thermal expansion of investigated $\mathrm{Pt}-\mathrm{Pd}$ alloys shows similar behavior, but in those intervals where specific electrical resistance decreases, thermal expansion increases and vice versa.

To define mechanical properties of alloys of the binary $\mathrm{Pt}-\mathrm{Pd}$ system, microhardness at room temperature, high-temperature tensile strength, and elongation in the temperature range of $1100-1400^{\circ} \mathrm{C}$ for pure platinum and PtPd10 and PtPd15 alloys was examined. Samples in the form of a wire (diameter $1.3 \mathrm{~mm}$ and length $50 \mathrm{~mm}$ ) were annealed at $1300^{\circ} \mathrm{C}$ for 3 hours, before the examination. Deformation rate dur-

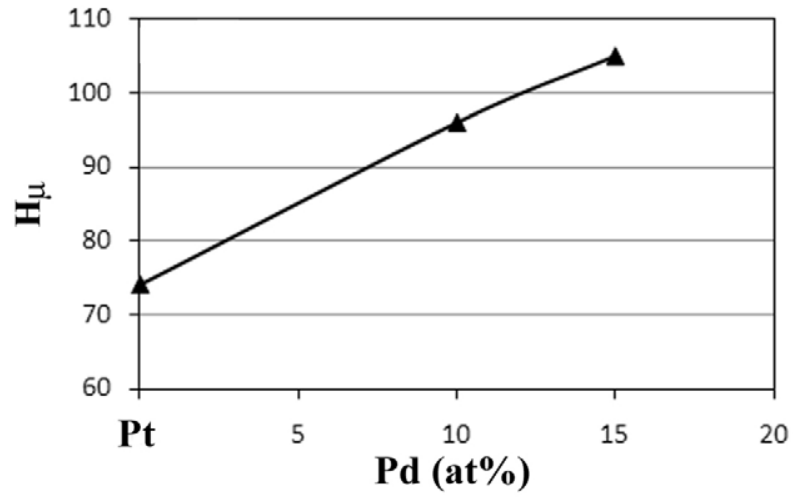

Fig. 6. Dependence of Pt-Pd alloys microhardness, $H \mu$, on palladium content at room temperature $\left(25^{\circ} \mathrm{C}\right)$.

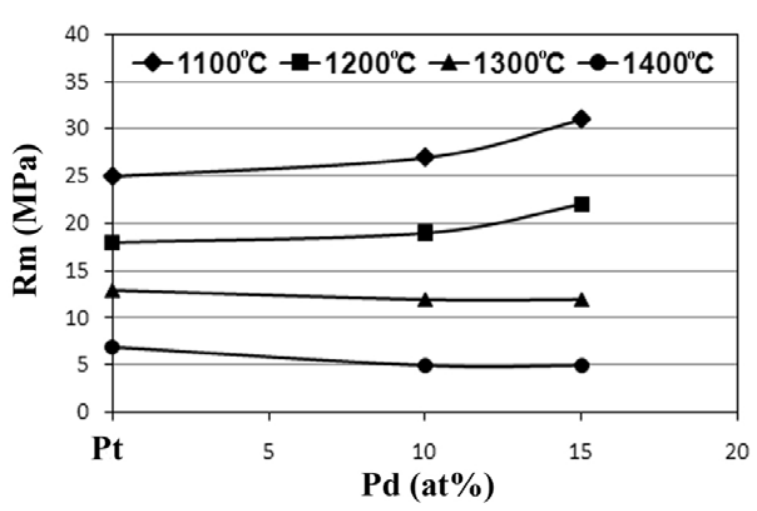

Fig. 7. Dependence of Pt-Pd alloys high-temperature tensile strength, $R_{\mathrm{m}}$, on palladium content in the temperature range $1100-1400^{\circ} \mathrm{C}$.

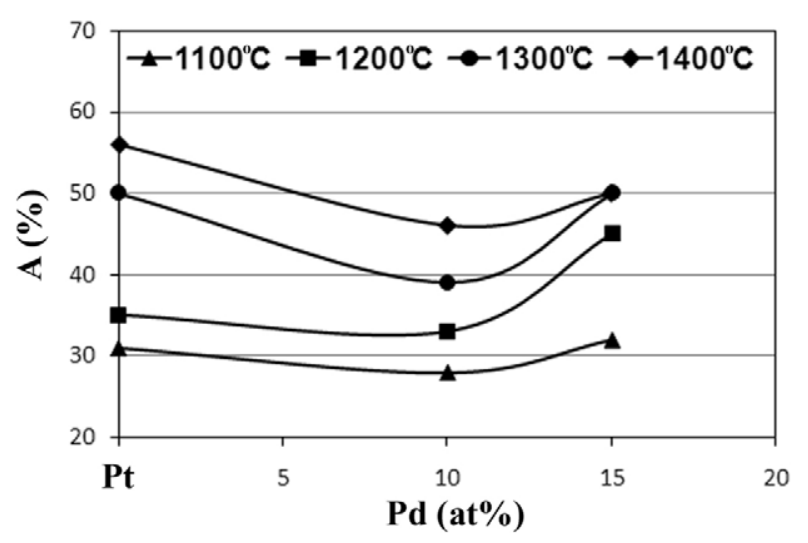

Fig. 8. Dependence of Pt-Pd alloys elongation, $A$, on palladium content in the temperature range $1100-1400{ }^{\circ} \mathrm{C}$.

ing testing was $6 \mathrm{~mm} \mathrm{~min}^{-1}$. Test results are shown in Figs. 6-8.

Microhardness of the alloys at room temperature in investigated concentration range (0-15\% 


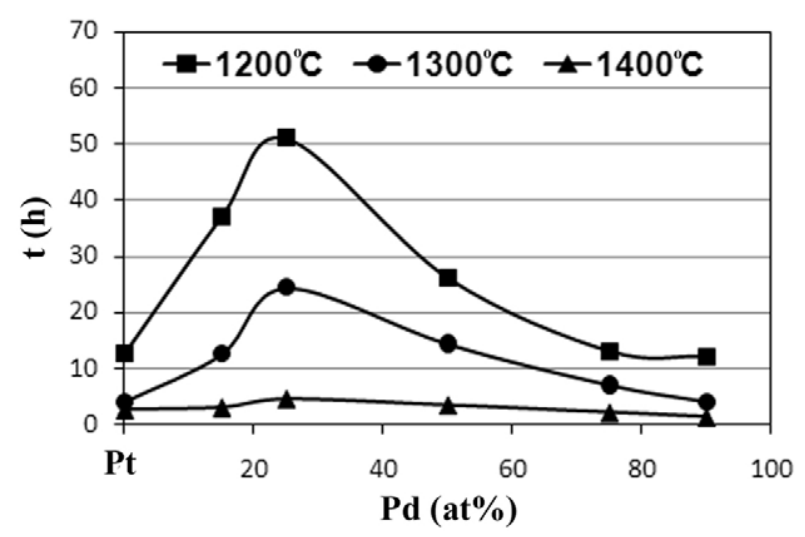

Fig. 9. Dependence of Pt-Pd alloys rupture time on palladium content, at a stress of $5 \mathrm{MPa}$, at different temperatures.

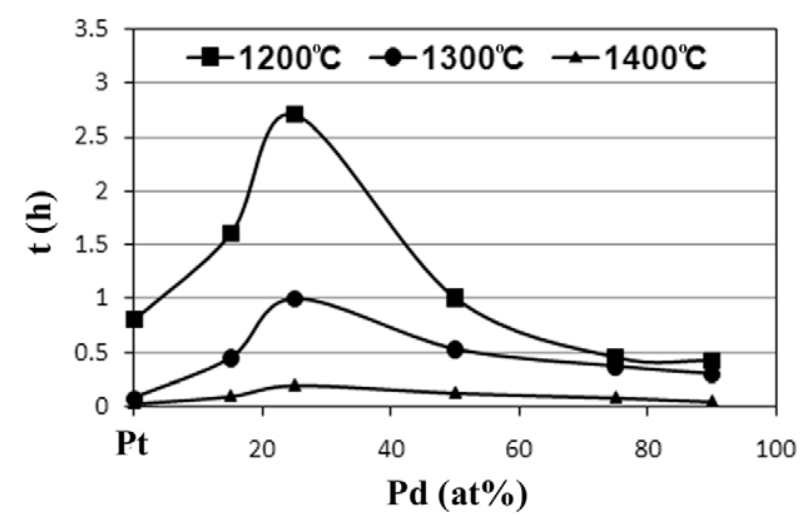

Fig. 10. Dependence of Pt-Pd alloys rupture time on palladium content, at a stress of $10 \mathrm{MPa}$, at different temperatures.

Pd) increases almost linearly (Fig. 6). Tensile hightemperature strength of tested Pt-Pd alloys slightly increases with increasing palladium content (Fig. 7), but the increase in test temperature causes a significant decline in measured values. Curves obtained for temperatures above $1300{ }^{\circ} \mathrm{C}$ show a constant decline in the value of tensile strength. Conversely, elongation of investigated alloys increases with increasing temperature (Fig. 8), while increasing of palladium content to $15 \%$ causes a slight increase in elongation values.

Results of the dependence of Pt-Pd alloys rupture time on palladium content in the temperature range $1200-1400{ }^{\circ} \mathrm{C}$, at a stress of $5 \mathrm{MPa}$, are shown in Fig. 9.

Results of the dependence of $\mathrm{Pt}-\mathrm{Pd}$ alloys rupture time on palladium content in the temperature range $1200-1400^{\circ} \mathrm{C}$, at a stress of $10 \mathrm{MPa}$, are shown in Fig. 10 .

Based on the obtained results (Figs. 9 and 10), it can be concluded that the high-temperature resistance of alloys in studied conditions increases with the increase of palladium content up to $25-27 \%$. This effect is especially observed at a temperature of $1200^{\circ} \mathrm{C}$. At $1300^{\circ} \mathrm{C}$ the effect is less pronounced while at $1400^{\circ} \mathrm{C}$ is completely lacking - alloying of platinum with palladium, in this case, does not lead to increased resistance at high temperatures.

Since melting temperature of palladium is lower compared to pure platinum, at high-temperature tests $\left(1300\right.$ and $1400^{\circ} \mathrm{C}$ ) and at high palladium contents, diffusion mobility of this metal in alloy significantly increases, resulting in a decrease in high-temperature stability of Pt-Pd system alloys.

The activation energy of creep of platinum alloys with $25-57 \% \mathrm{Pd}$ is close to values for molten metals and at $1000^{\circ} \mathrm{C}$ is $252 \mathrm{~kJ} \mathrm{~mol}^{-1}$ [26]. The close values of activation energy of creep of platinum, palladium, and their alloys, as well as a slight change in the diffusion coefficient of components in the $\mathrm{Pt}-\mathrm{Pd}$ system, explain the relatively low-temperature resistance of alloys from this system, which was confirmed by our results.

The investigated alloys with $15-50 \%$ Pd have high-temperature stability maximum which, with temperature increase, changes very slightly. So, the increase in temperature leads to a reduction of the hardening effect of platinum with palladium, with shifting the maximum to the side of metal with a higher melting point, in this case, to platinum.

Dependence of creep rate of Pt-Pd system alloys on palladium content, at $1000^{\circ} \mathrm{C}$ and stresses of 25 , 17.8, 10 and 4.5 $\mathrm{MPa}$ is shown in Fig. $11 \mathrm{a}-\mathrm{d}$.

Creep rate increases with increasing palladium content, making it clear that palladium does not affect blocking of dislocations which represents an important mechanism with considerable influence on hardening of platinum when alloyed with platinum group metals.

The dependence of rupture time of Pt-Pd system alloys on palladium content, at $1000^{\circ} \mathrm{C}$ and stresses of $25 \mathrm{MPa}$ and $17.8 \mathrm{MPa}$ is shown in Fig. 12a,b.

Rupture time of investigated $\mathrm{Pt}-\mathrm{Pd}$ alloys decreases with increasing content of palladium, but in the concentration area of $20-40 \% \mathrm{Pd}$ a slight increase in the value of rupture time was noticed. All in all, it can be concluded that alloying of platinum with palladium does not lead to a significant increase in hightemperature stability.

Numerous studies have determined that the characteristics of high-temperature strength, creep resistance, in particular, depends on the activation energy of sliding along grain boundaries, and this is more pronounced when the difference of atomic diameters of base metal and alloying element is larger [27]. It was concluded that the share of intergrain moving (sliding along grain boundaries) in total displacement, during creeping of samples based on platinum alloys, at high temperatures can reach up to $10 \%$, and consequently, by preventing sliding at grain boundaries durability of platinum alloys at high temperatures substantially increases. 

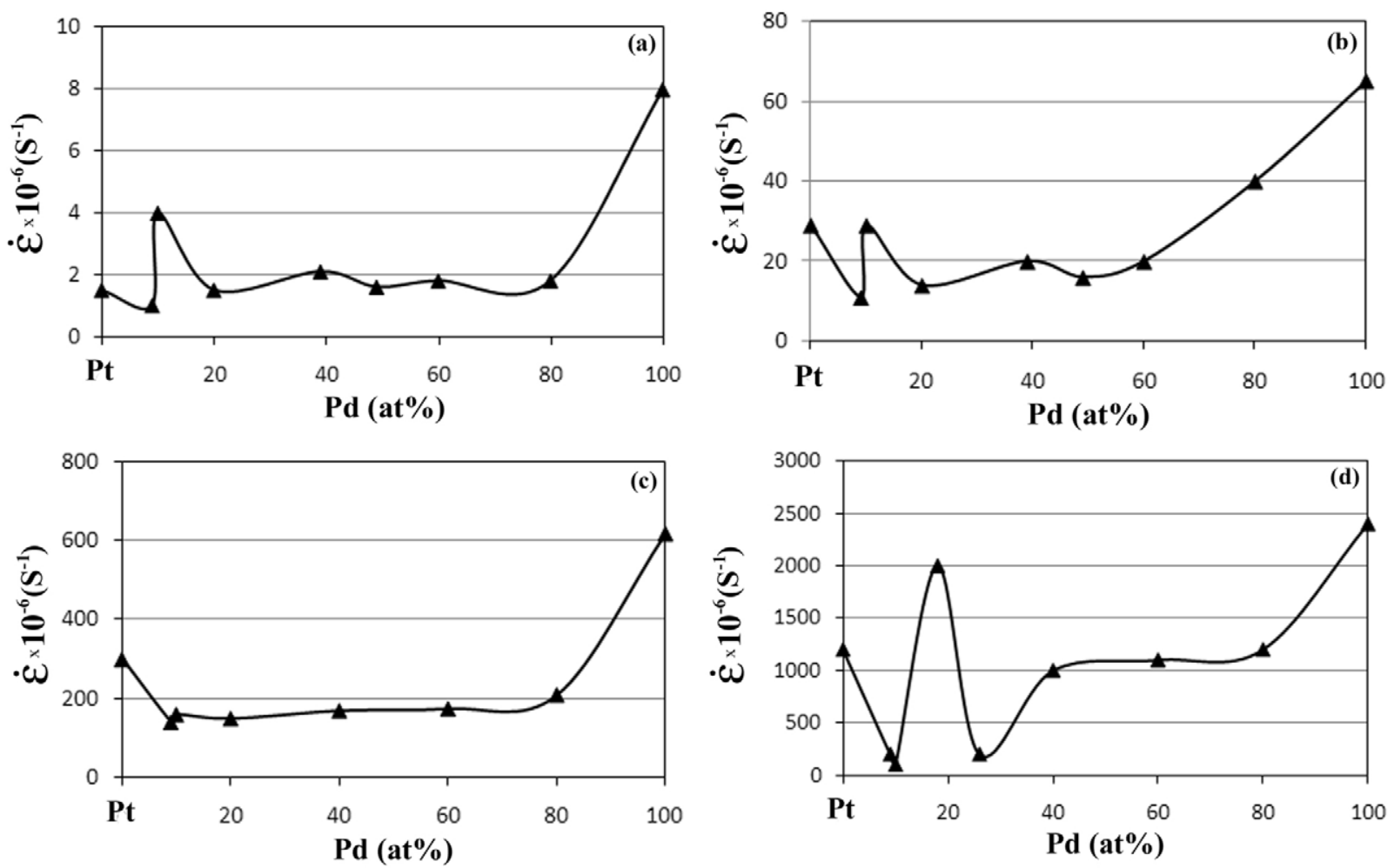

Fig. 11. Dependence of Pt-Pd alloys creep rate on palladium content at $1000^{\circ} \mathrm{C}$ at a stress of a) $\left.25 \mathrm{MPa}, \mathrm{b}\right) 17.8 \mathrm{MPa}$, c) $10 \mathrm{MPa}$ and d) $4.5 \mathrm{MPa}$.

Atomic diameters of platinum and palladium (Pt-0.1388 nm and Pd-0.1370 nm [26]) are very similar. Also, the melting temperature of palladium is lower than melting temperature of platinum (Pt$\left.1768^{\circ} \mathrm{C}, \mathrm{Pd}-1555^{\circ} \mathrm{C}[28]\right)$, so palladium has little impact on platinum hardening, as our results confirmed.

Starting from the basic equation Sherby [27] for creep rate:

$$
\varepsilon=A \gamma^{m} D(\sigma / E)^{n}
$$

High-temperature creep resistance of platinum and its solid solutions with palladium increases with increasing the modulus of elasticity, $E$, and stress, $\sigma$, and decreasing the diffusion coefficient, $D$, and energy of grid errors, $\gamma$. In Eq. (1), $A$ is a constant dependent on temperature and $n, m$ are stress exponents.

Forming solid solutions with platinum, palladium slightly slows down high-temperature creep which does not result in increased lifetime of platinum alloys.

According to equation Suzuki [29], critical stress required for further creep is proportional to concentration of alloying element and to difference of energy of errors of base metal and alloying element:

$$
\sigma_{\mathrm{kr}}=\frac{2 h}{V b} H C_{\mathrm{cp}}\left(1-C_{\mathrm{cp}}\right) \frac{1-\mathrm{e}^{-Q / R T}}{\left(1-C_{\mathrm{cp}}\right)\left(1-\mathrm{e}^{-Q / R T}\right)},
$$

Ta ble 1. Grid errors energy for platinum metals [26]

\begin{tabular}{ccccc}
\hline & $\mathrm{Pt}$ & $\mathrm{Rh}$ & $\mathrm{Ir}$ & $\mathrm{Pd}$ \\
\hline$\gamma\left(\mathrm{KJ} \mathrm{m}^{-2}\right)$ & 120 & 180 & 190 & 90 \\
\hline
\end{tabular}

where

$$
H=\left(\gamma_{\mathrm{A}}-\gamma_{\mathrm{B}}\right) \frac{V}{2 h},
$$

$\sigma_{\mathrm{kr}}$ is critical stress, $h$ is $1 / 2$ width of lattice defects, $V$ is molar volume of alloy, $b$ is Burgers vector, $\gamma_{\mathrm{B}}$ is lattice energy defect of base metal, $\gamma_{\mathrm{A}}$ is lattice energy defect of alloying element, $C_{\mathrm{cp}}$ is average concentration of alloying element, $Q$ is activation energy, $R$ is gas constant, and $T$ is absolute temperature.

For most platinum alloys which form a continuous series of solid solutions, it can be assumed that the larger the concentration of the alloying element, as well as the greater the difference in energy values of grid error of platinum and that element, the greater is strengthening of solid solution based on platinum.

The values of grid errors energy of platinum metals [26] are given in Table 1.

If these energy values of grid errors of platinum and palladium are inserted into Eq. (2), it can be concluded that when platinum is alloyed with palladium, 

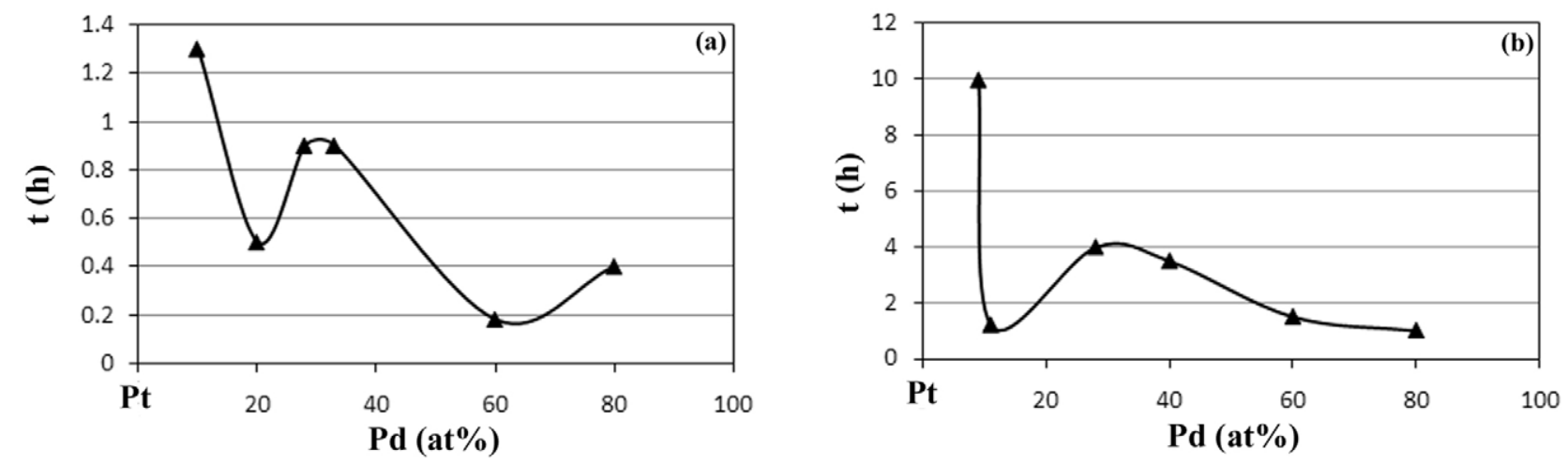

Fig. 12. Dependence of Pt-Pd alloys rupture time on palladium content at $1000^{\circ} \mathrm{C}$, at a stress of a) $25 \mathrm{MPa}$ and b) $17.8 \mathrm{MPa}$.

no major critical stress is needed for creep process.

To reduce creep rate of platinum alloys, according to Eq. (1), it is necessary to reduce grid errors energy of solid solution. The value of grid errors energy of platinum and its alloys can be judged by dislocation structure [24].

Alloying of platinum with palladium practically does not change the size of cavities and dislocation density in its walls. Specifically, palladium does not lead to a significant fragmentation (splitting) of platinum dislocations, neither significantly reduces the grid errors energy. In accordance with Eq. (1), alloying of platinum with palladium shows no influence on the high-temperature creep.

Our results are in accordance with:

a) $\gamma_{\mathrm{Pt}} \approx \gamma_{\mathrm{Pt}+\mathrm{Pd}}$ (grid errors energy of platinum and its binary alloys with palladium [30] at temperatures up to $900^{\circ} \mathrm{C}$ ) and

b) $\zeta_{\mathrm{Pt}} \approx \zeta_{\mathrm{Pt}+\mathrm{Pd}}$ (creep rate of platinum and its alloys with palladium [29], at temperatures up to $\left.900^{\circ} \mathrm{C}\right)$.

However, with prolonged retention of samples at temperatures above $900^{\circ} \mathrm{C}$, due to increased affinity of palladium to oxygen, oxidation and evaporation of palladium occurs, which leads to a reduction in the hardening effect of platinum with this metal, as confirmed by our results.

\section{Conclusion}

The paper presents results of mechanical properties investigations of Pt-Pd system alloys at room and elevated temperatures. Based on these results following can be concluded:

- The hardness of tested alloys increases sharply to $40 \% \mathrm{Pd}$, and then slightly decreases.

- Maximum values for tensile strength occur at alloys containing 40-70\% Pd while the relative elongation increases slightly with increasing palladium content.

- The specific electrical resistance increases with increasing palladium content up to $40 \%$, then decreases to $50 \% \mathrm{Pd}$, increases to $60 \% \mathrm{Pd}$ and with further increasing of palladium contents in alloy drops significantly. The relative thermal expansion of investigated alloys belonging to $\mathrm{Pt}-\mathrm{Pd}$ binary system shows similar behavior, but in those concentration intervals where specific electrical resistance decreases, thermal expansion increases, and vice versa.

- The microhardness of alloys at room temperature in investigated concentration range $(0-15 \% \mathrm{Pd})$ increases almost linearly.

- The high-temperature tensile strength of tested Pt-Pd alloys slightly increases with increasing content of palladium, but test temperature increase causes a significant decrease in measured values. For a temperature above $1300^{\circ} \mathrm{C}$, curves show a constant decline in tensile strength values. On the contrary, elongation of investigated alloys increases with increasing temperature, while increasing of palladium content to $15 \%$ causes a slight increase in elongation values.

- Creep speed increases with increasing content of palladium, which is why it is clear that it does not affect the blocking of dislocations which represents an important mechanism with considerable influence on the process of hardening of platinum with platinum group metals.

- Rupture time of investigated Pt-Pd alloys decreases with increasing content of palladium, but in the concentration area of $20-40 \% \mathrm{Pd}$ a slight increase in the value of rupture time was noticed.

- Alloying of platinum with palladium practically does not change the size of cavities and density of dislocations within its walls. Specifically, palladium does not lead to a significant fragmentation (splitting) of platinum dislocations, neither significantly reduces the grid errors energy and, therefore, alloying of platinum with palladium shows no influence on the hightemperature creep rate.

- The close values of the creep activation energy of platinum, palladium, and their alloys, as well as a slight change in the diffusion coefficient of components in the Pt-Pd system significantly explain the 
relatively low-temperature resistance of alloys of the system, which was confirmed by our results.

\section{Acknowledgements}

The authors are grateful to the Ministry of Education and Science of the Republic of Serbia (Project No. 34029) for financial support.

\section{References}

[1] Gavin, H.: Platinum Met. Rev., 54, 2010, p. 166. doi:10.1595/147106710x500125

[2] Preston, E.: Platinum Met. Rev., 4, 1960, p. 48.

[3] Stokes, J.: Platinum Met. Rev., 31, 1987, p. 54.

[4] Ning, Y., Yang, Z., Zhao, H.: Platinum Met. Rev., 4, 1996 , p. 80.

[5] Yuantao, N., Zhengfen, Y.: Platinum Met. Rev., 43, 1999 , p. 62.

[6] Trumić, B., Stanković, D., Trujić, V.: J. Min. Metall. Sect. B, 45, 2009, p. 79. doi:10.2298/JMMB0901079T

[7] Wu, B., Liu, G.: Platinum Met. Rev., 41, 1997, p. 81.

[8] Funabikia, M., Yamada, T., Kayanoa, K.: Catal. Today, 10, 1991, p. 33. doi:10.1016/0920-5861(91)80072-H

[9] Biggs, T., Taylor, S. S., van der Lingen, E.: Platinum Met. Rev., 49, 2005, p. 2. doi:10.1595/147106705x24409

[10] Wright, J. C.: Platinum Met. Rev., 46, 2002, p. 66.

[11] Xiao, F., Zhao, F., Mei, D., Mo, Z., Zeng, B.: Biosens. Bioelectron., 24, 2009, p. 3481. doi:.1016/j.bios.2009.04.045

[12] Knosp, H., Holliday, R. J., Corti, C. W.: Gold Bull., 36, 2003, p. 93. doi:10.1007/BF03215496

[13] Shiraishi, T., Takuma, Y., Miura, E., Fujita, T., Hisatsune, K.: Mater. Sci. Eng. B, 140, 2007, p. 147. doi:10.1016/j.mseb.2007.03.022

[14] Hyun, S., Kraft, O., Vinci, R. P.: Acta Mater., 52, 2004, p. 4199. doi:10.1016/j.actamat.2004.05.034
[15] Rousselot, S., Gazeau, A., Guay, D., Roue, L.: Electrochim. Acta, 55, 2010, p. 611. doi:10.1016/j.electacta.2009.09.014

[16] Takenaka, K., Togashi, N., Nishiyama, N., Inoue, A.: Intermetallics, 18, 2010, p. 1969. doi:10.1016/j.intermet.2010.02.045

[17] Deng, H., Hu, W., Shu, X., Zhao, L., Zhang, B.: Surf. Sci., 517, 2002, p. 177. doi:10.1016/S0039-6028(02)02061-7

[18] Luyten, J., De Keyzer, J., Wollants, P., Creemers, C.: Calphad, 33, 2009, p. 370. doi:10.1016/j.calphad.2008.10.007

[19] Zhang, H-X., Wang, C., Wang, J-Y., Zhai, J-J., Cai, W-B.: J. Phys. Chem. C, 114, 2010, p. 6446. doi:10.1021/jp100835b

[20] http://www1.bipm.org/cc/CCT/Allowed/22/ CCT03-10.pdf

[21] Ongrai, O., Pearce, J. V., Machin, G., Sweeney, S. J.: Int. J. Thermophys, 31, 2010, p. 1506. doi:10.1007/s10765-010-0782-0

[23] Ramirez Caballero G. E., Balbuena, P. B.: Mol. Simul., 32, 2006, p. 297. doi:10.1080/08927020600684337

[23] Hansen, P. L., Molenbroek, A. M., Ruban, A. V.: J. Phys. Chem. B, 101, 1997, p. 1861. doi:10.1021/.jp962771o

[24] Trumić, B., Gomidželović, L., Trujić, V., Krstić, V., Stanković, D.: Hem. Ind., 66, 2012, p. 395. (in Serbian) doi:10.2298/HEMIND110718106T

[25] Vidal-Iglesias, F. J., Solla-Gullon, J., Montiel, V., Feliu, J. M., Aldaz, A.: J. Power Sources, 171, 2007, p. 448. doi:10.1016/j.jpowsour.2007.06.015

[26] Ritvin, E. I., Medovoj, L. A.: Influence of Physical and Chemical Marks on Refractoriness of Metallic Materials. Moskva, Nauka 1974. (in Russian)

[27] Savickij, E. M., Polakova, V. P., Gorina, N. B., Roshan, N. R.: Metallography of Platinum Metals. Moskva, Metallurgija 1975. (in Russian)

[28] http://www.chemicool.com

[29] Ritvin, E. I.: Heat Resistance of Platinum Alloys. Moskva, Metallurgija 1987. (in Russian) 